\title{
A Benign Giant Prostate Hyperplasia Causing Fatal Death without any Prior Symptomatology, a Rare Case Study
}

\section{Juna Musa ${ }^{1 *}$, Elton Cekaj ${ }^{2}$, Mohammed K Badi ${ }^{3}$, Carlos Rivera ${ }^{4}$, Edlira Horjeti $^{5}$, Henri Fero ${ }^{6}$, Loran Rakovica ${ }^{7}$ and Ali Guy ${ }^{8}$}

${ }^{1}$ Postdoctoral Research Fellow, Department of Surgery, Mayo Clinic, Rochester,

Minnesota, USA

${ }^{2}$ Radiologist, Regional Hospital of Durres, Albania

${ }^{3}$ Research Fellow, Department of Neurology, Mayo Clinic, Florida, USA

${ }^{4}$ Research Fellow, General Surgery Department, Metabolic and Bariatric Institute,

Cleveland Clinic, Florida, USA

${ }^{5}$ Family Doctor, Department of Family Medicine, Tirane, Albania

${ }^{6}$ Medical Student, Faculty of Medicine, Univeriteti of Tirana, Albania

${ }^{7}$ Faculty of Medicine, University of Prishtina, Kosovo

${ }^{8}$ Department of Physical Medicine and Rehabilitation, New York University, School of

Medicine, NYU Medical Center, New York, USA

*Corresponding Author: Juna Musa, Postdoctoral Research Fellow, Department of

Surgery, Mayo Clinic, Rochester, Minnesota, USA.
Received: March 31, 2020

Published: April 08, 2020

(C) All rights are reserved by Juna Musa., et al.

\begin{abstract}
Benign Prostatic Hyperplasia (BPH) is a common progressive disease of ageing men that is characterized prostate enlargement leading to lower urinary tract symptoms. Prostate volume have been shown to directly correlate with age, men over the age of 50 have a $40 \%$ risk of BPH and those over 80 years have $90 \%$ risk. Giant prostatic hyperplasia (GPH) is a rare form of BPH and it is commonly seen in patients neglecting their symptoms or inadequately treated disease. BPH symptoms vary with the grade of the disease ranging from asymptomatic to incontinence, nocturia, hematuria, dysuria and urinary retention in more severe forms such as in GPH. Herein we present a case of a 53 years old male patient that presented with altered mental status, pale skin and urinary retention. During the ultrasound examination a huge prostate gland was discovered.

Keywords: Benign Prostatic Hyperplasia (BPH); Giant Prostatic Hyperplasia (GPH); Fatal Death
\end{abstract}

\section{Introduction}

The prostate gland is a flattened, conical structure orientated in the coronal plane where the apex points downward and it is located just above the deep fascia of the urogenital diaphragm. Its anterior surface is directed toward the symphysis, from which it is separated by adipose tissue and periprostatic veins. The normal prostate measures approximately $4 \times 3 \times 3 \mathrm{~cm}$ and weighs roughly 15 to 20 grams (g) [1]. Typically, the gland size increases after 40 years of age [2].

Benign prostatic hypertrophy (BPH) is a benign nodular enlargement of the prostate gland.

Histologically, changes of BPH may be predominantly glandular, less commonly interstitial [2] or both. The effects of BPH on the urethra, bladder, or kidneys are related to the size and predominant location of the mass [2,3]. Nodular prostatic enlargement is the most common form and can result in constriction of the urethra and subsequent bladder obstruction due to affliction of the central gland. BPH is a common condition in men and is often associated with increased age; hyperplasia can exceed $100 \mathrm{~g}$ only in
$4 \%$ of men older than 70 years and the [12] term Giant prostatic hyperplasia (GPH) is defined as a prostate weight of over 500g [13]. Although no uniform criteria exist. Lower Urinary Tract Symptoms (LUTS) secondary to prostatic enlargement, such as urinary hesitancy, intermittency, urgency and nocturia, can have a significant impact on patient quality of life (QoL) and may be relieved only partially with [14] medical management. Transrectal ultrasound is the examination of choice to evaluate $\mathrm{BPH}$, but huge prostate needs to be evaluated with a CT or MRI. On CT, the enlarged gland nodules can have both high and low-attenuation regions in addition to variable enhancement. Coarse calcifications are common in BPH. On $\mathrm{CT}$, as a general rule, the prostate is not considered to be enlarged if a section obtained $1 \mathrm{~cm}$ above the symphysis does not include the prostate.

Unequivocal enlargement of the prostate is diagnosed if the prostate is seen on sections $2-3 \mathrm{~cm}$ or more above the symphysis. On these sections, the prostate, if enlarged, is usually surrounded by the bladder. On ultrasound, the prostate volume is measured with this formula: $\Pi / 6 \mathrm{x}$ height $\mathrm{x}$ width $\mathrm{x}$ length, and to calculate the weight this must be multiplied by 1.05 . On MRI, the appear- 
ance of GPH varies depending on the imaging sequence used (T1or T2-weighted) and the histological type (glandular, stromal, or mixed). GPH is indistinguishable from prostate carcinoma on CT, and despite the aforementioned features, MRI is also unable to distinguish benign from malignant prostate [4-8]. Patients with large prostates (> $80-100 \mathrm{~mL}$ ) and moderate to severe LUTS that are refractory to medical therapy can be surgically removed [15].

Prostatic artery embolization could also be a safe method of treatment option as presented in previous case reports $[13,15]$. In some people, the prostate enlarges massively; eventually. Prostate weighing more than $700 \mathrm{~g}$ was described in few cases all around the world $[9,10]$ rare pathology, to the best of our knowledge there are only 10 cases previously reported wherein the prostate weighted more than $700 \mathrm{~g}$ [16]. In this study we report a case of GPH (718g) in a 54 years old male, who presented with altered mental state/ confusion and urinary retention.

\section{Case Presentation}

A 54 year old patient presented to the emergency room with fatigue, altered mental state, visual disturbances, nausea and abdominal distention. Pruritus and also nail atrophy were noted indicating uremia.

Abdominal ultrasound was unable to differentiate the anechoic cystic masses and the prostate so a head and abdominal CT were performed. Contrast media was not administered because of high level of serum creatinine $(9 \mathrm{mg} / \mathrm{dl})$ also indicating renal insufficiency, a rare finding in patients with $\mathrm{BPH}$, but considering the size of the prostate gland in our patient, it is the constriction of the urethra that most likely leads increased the intratubular pressure thus contributing directly to the glomerular filtration rate decline.

\section{Imaging findings}

Abdominal CT showed hydronephrosis bilaterally with dilated and tortuous ureters. Additionally, the imaging showed a large stone in the left renal pelvis and several small stones in the distal left ureter and the urinary bladder (Figure 1-4).

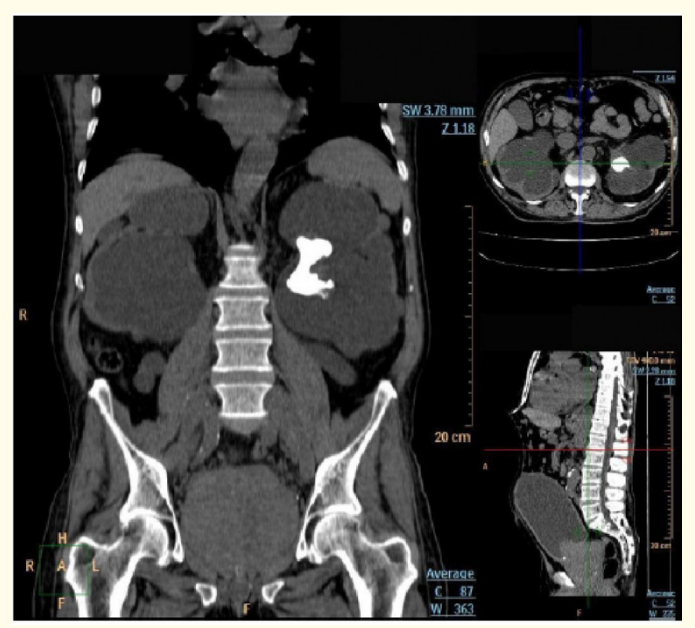

Figure 1: Coronal CT image notes the high grade of hydronephrosis on both kidneys and the big coral like stone on left renal pelvis.

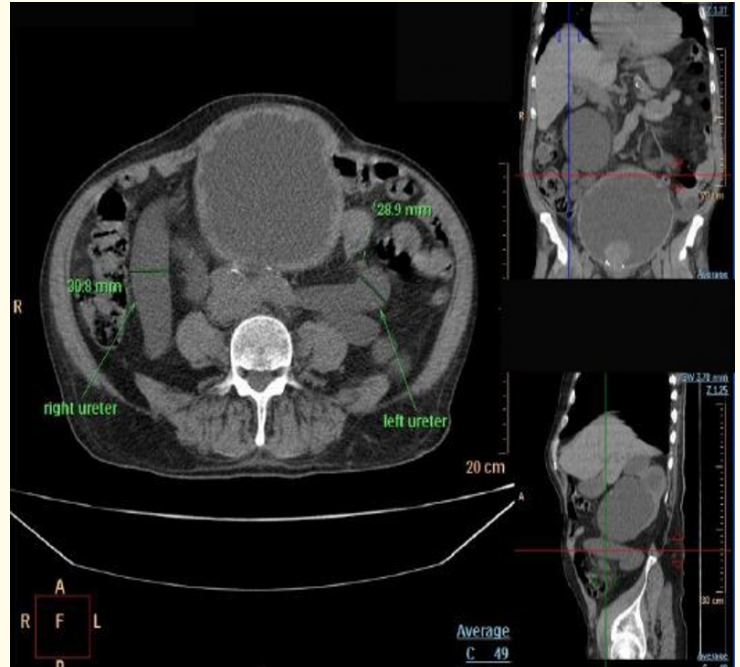

Figure 2: Axial CT shows dilated and tortuous ureters on both sides (arrows).

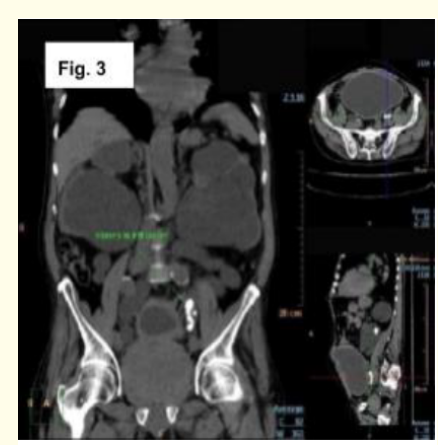

Figure 3: Coronal CT of the stones on the distal third of left ureter and the small stones in urinary bladder on axial slice of figure 4.

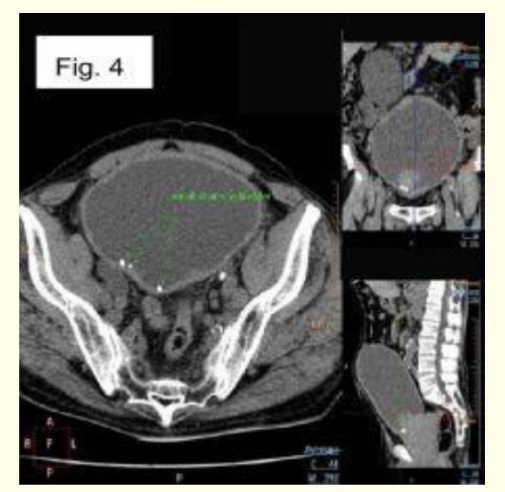

Figure 4: Axial CT view: Note the small stones in the urinary bladder.

Moreover, the unexpected finding was the enormous size of the prostate, with a total volume $\sim 684 \mathrm{ml}=106.8 \times 101.9 \times 120.1$ $\mathrm{cm}$ or $718.2 \mathrm{gm}$. comparatively, the residual urine volume in the bladder was almost 1.71 liters (Figure 5-7). The residual urine was removed via transabdominal puncture. Unfortunately, the patient died four days due to cerebral coma. 


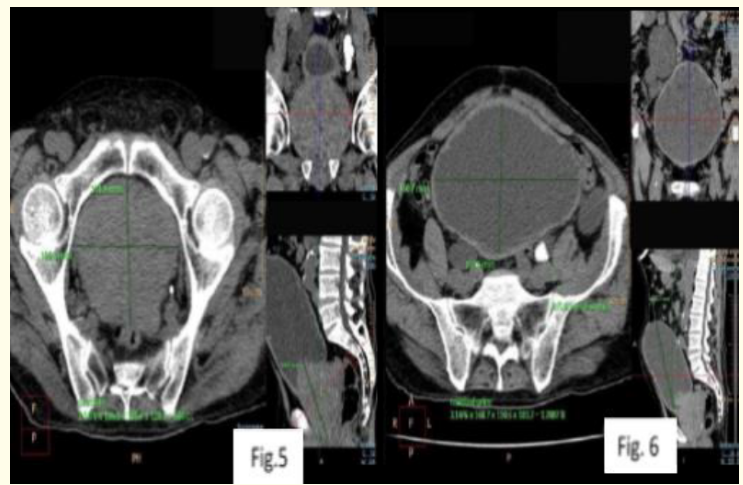

Figure 5 and 6: Figure 5: Displays the whole enormous of prostate volume $\sim 684 \mathrm{ml}$, and shape changes and figure 6: Measures the giant volume of residual urine: $\sim 1.7087$ Liter.

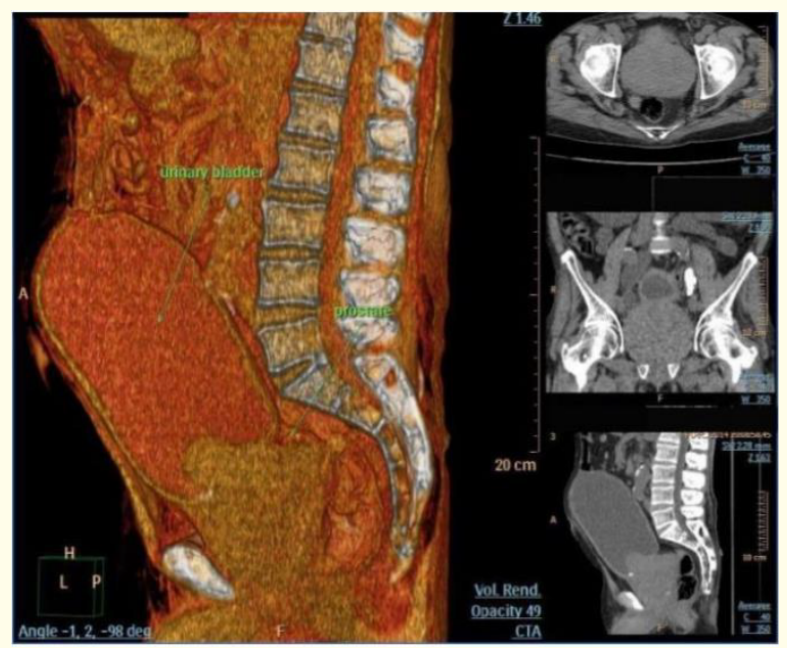

Figure 7: Volume rendering reconstruction view: Note the prostate volume and residual urine volume.

\section{Discussion}

GPH is one of the most common diseases affecting men due to aging with a negative impact on quality of life [17]. Prostatic hyperplasia is considered to be due to the proliferation of epithelial and stromal cell, impairment of programmed cell death (apoptosis) or both [18].

It is seen that Androgens play an important role mediating the balance between proliferation and cell death [19]. Additionally, inflammation assessed by cytological and immune-histochemical parameters are associated with a high International Prostate Symptom Scores (IPSS) and a higher prostate volume, as demonstrated in previous studies [20].

Multiple studies have shown evidence that genetics may play a role during the inflammatory process [21]. The CLUE II study failed to associate BPH with any of the 17 single nucleotide polymorphisms in genes involved in obesity. Polymorphisms located in the regions of Lymphotoxin beta receptor (LT-beta-R), associated with inflammatory disorders has been significantly associated with BPH [21]. However, GPH genesis is still unclear and not fully understood; mutations of certain proto oncogenes, such as Ras and C-erbB-2 factors that continuously develop cellular proliferation, has been postulated to be involved, as well as loss of suppressor genes such as p53 suppressor gene.

Ultrasound imaging may have certain limitations at assisting the evaluation and diagnosis due to the size of the prostate, requiring alternative more expensive devices such as CT scan or MRI that cannot be used randomly at point of care. Nevertheless, therapeutic surgical options decisions (laparoscopic vs open surgery) are based on size comorbidities and coexisting urologic medical problems [12].

To the extent of our knowledge there is no consensus established on the upper limit of the weight of the prostate gland. Limitations of this study include the single-center, retrospective nature, rarity of the case and lack of extensive literature on management of GPH. Further studies are needed to evaluate and achieve a consensus in the treatment of GPH.

\section{Conclusion}

GPH is an under recognized pathology of the prostate, that could end up in severe complications or death. Few cases have been reported to this date making literature very scarce. GPH should be assessed and managed by a multidisciplinary medical team in the way to improve the results. In addition, physicians should be aware of these extreme cases in elderly men, to detect them as soon as possible. A periodic check-up, prostate specific antigen (PSA) evaluation and an abdominal ultrasound scan is recommended to prevent this progressive disease reaching extreme limits.

\section{Conflicts of Interest}

No conflict exists.

\section{Funding Statement}

No funding.

\section{Bibliography}

1. Paul Martin and Hassan Resvi. "Benign Prostatic Hyperplasia (BPH) and Lower Urinary Tract Symptoms (LUTS) in Men".

2. McNeal JE. "The prostate gland. Morphology and pathobiology”. Monograph Urology 4 (1983): 5-13.

3. Berry SJ., et al. "The development of human benign prostatic hyperplasia with age". The Journal of Urology 132 (1984): 474479.

4. Maio A and Rifkin MD. "Magnetic resonance imaging of prostate cancer: Update". Topics in Magnetic Resonance Imaging 7 (1995): 54-68.

5. Dennis MA and Donohue RE. "Computed tomography of prostatic abscess". Journal of Computer Assisted Tomography 9 (1985): 201-202. 
6. Ling D., et al. "Prostatic carcinoma and benign prostatic hyperplasia: Inability of MR imaging to distinguish between the two diseases". Radiology 158 (1986): 103-107.

7. Schiebler ML., et al. "Prostatic carcinoma and benign prostatic hyperplasia: Correlation of high-resolution MR and histopathologic findings". Radiology 172 (1989): 131-137.

8. Shivadeo S Bapat., et al. "Does estimation of prostate volume by abdominal ultrasonography vary with bladder volume: A prospective study with transrectal ultrasonography as a reference". Indian Journal of Urology 22.4 (2006): 322-325.

9. E Akpo and M Akpo. "Giant Benign Prostatic Hyperplasia in A Nigerian: Report of A Case". The Internet Journal of Urology 8 (2010): 1 .

10. Joseph Maliakal., et al. "Giant Prostatic Hyperplasia Fourth largest prostate reported in medical literature". Sultan Qaboos University Medical Journal 14-2 (2014): 253-256.

11. Coakley F V and Hricak H. "Radiologic Anatomy of The Prostate Gland: A Clinical Approach". Radiologic Clinics of North America 38.1 (2000): 15-30.

12. Aghamir SMK., et al. "Giant benign prostatic hyperplasia: A case report”. Urology Case Reports (2019): 101051.

13. Kava B., et al. "Prostate Artery Embolization for Giant Prostatic Hyperplasia”. Journal of Vascular and Interventional Radiology 26.10 (2019): 1583-1585.

14. De Assis AM., et al. "Prostatic Artery Embolization for Treatment of Benign Prostatic Hyperplasia in Patients with Prostates and gt; 90 g: A Prospective Single-Center Study". Journal of Vascular and Interventional Radiology 26.1 (2015): 87-93.

15. Mathevosian S., et al. "Prostate Artery Embolization for Giant Prostatic Enlargement: Short-Term Efficacy and Safety". Journal of Vascular and Interventional Radiology 30.11 (2019): 1820-1823.

16. Domínguez A., et al. "Giant prostatic hyperplasia: Case report of 3987 mL”. Urology 88 (2016): e3-e4.

17. Wei JT., et al. "Urologic diseases in America project: Benign prostatic hyperplasia”. The Journal of Urology 173.4 (2005): 1256-1261.

18. Isaacs JT. "Antagonistic effect of androgen on prostatic cell death". Prostate 5.5 (1984): 545-557.

19. Robert G., et al. "Inflammation in benign prostatic hyperplasia: A 282 patients' immunohistochemical analysis". Prostate 69.16 (2009): 1774-1780.

20. Lei YMK., et al. "Association of Variants in Genes Related to the Immune Response and Obesity with Benign Prostatic Hyperplasia in CLUE II". Clinics and Research in Hepatology and Gastroenterology 39.1 (2015): 919.
21. Lee SH., et al. "Association of LT $\beta$ R gene polymorphisms with prostate volume in benign prostatic hyperplasia in the Korean population". Genetics and Molecular Research 14.4 (2015) 18607-18615.

\section{Assets from publication with us}

- Prompt Acknowledgement after receiving the article

- Thorough Double blinded peer review

- Rapid Publication

- Issue of Publication Certificate

- High visibility of your Published work

Website: https://www.actascientific.com/

Submit Article: https://www.actascientific.com/submission.php Email us: editor@actascientific.com

Contact us: +919182824667 